\title{
Evaluation of Elemental and Chemical Compositions of Some Fuelwood Species for Energy Value
}

\author{
A. M. Dadile $\mathbb{D}^{\mathrm{D}},{ }^{1,2}$ O. A. Sotannde, ${ }^{1}$ B. D. Zira, ${ }^{1}$ M. Garba, ${ }^{1}$ and I. Yakubu ${ }^{2}$ \\ ${ }^{1}$ Department of Forestry and Wildlife, Faculty of Agriculture, University of Maiduguri, Maiduguri, Borno State, Nigeria \\ ${ }^{2}$ Department of Forestry and Wildlife Management, Faculty of Agriculture, Federal University Gashua, Gashua, \\ Yobe State, Nigeria
}

Correspondence should be addressed to A. M. Dadile; abubakardadile@gmail.com

Received 9 March 2020; Revised 15 June 2020; Accepted 23 June 2020; Published 27 July 2020

Academic Editor: Nikolaos D. Hasanagas

Copyright (c) 2020 A. M. Dadile et al. This is an open access article distributed under the Creative Commons Attribution License, which permits unrestricted use, distribution, and reproduction in any medium, provided the original work is properly cited.

Fuelwood species are a crucial part of the ecosystem; they provide energy for cooking, heating, and lightening for both domestic and industrial uses. As a result of their value, there is a need for frequent evaluation of elemental and chemical compositions for management and conservation purposes. Since fuelwood is the most common and cheapest source of energy in both rural and urban areas in northern Nigeria, the study area is facing serious challenges due to indiscriminate felling of trees for energy use, irrespective of species quality for combustion. Therefore, ten fuelwood species were selected for this study. The selected trees were harvested at Dbh level, replicated three times. Four fuel materials were obtained from each tree sample; these include wood without bark (100\% wood sample), wood with $5 \%$ bark inclusion, wood with $10 \%$ bark inclusion, and whole bark samples and they were evaluated for their inherent elemental and chemical compositions by employing ASTM and TAPPI methods. The results showed that there were significant differences in the tree species and fuel material types obtained from all the ten fuelwood species used. The results of carbon content ranges from $49.54 \%$ in A. sieberiana to $50.98 \%$ in A. leiocarpus. Meanwhile, the addition of $5 \%$ and $10 \%$ bark reduces carbon content of wood by $1.25 \%$ and $2.74 \%$, respectively. Nitrogen content ranged from $0.31 \%$ in $A$. leiocarpus to $1.00 \%$ in A. sieberiana. Among the fuel materials used, isolated bark contained approximately $0.45 \%$ nitrogen content compared with wood without bark. Among the tree species, hydrogen content ranged from 3.99\% in P. reticulatum to $4.66 \%$ in $C$. arereh. The variation in sulphur contents ranged from $0.24 \%$ in C. arereh to $0.93 \%$ in A. sieberiana. Lignin content ranged from $10.68 \%$ in A. sieberiana to $25.39 \%$ in A. leiocarpu and extractive content values ranged from $7.31 \%$ in $A$. leiocarpus to $19.33 \%$ in $P$. reticulatum. Meanwhile, the fuelwood species observed in this study with higher percentage of carbon, hydrogen, and lignin and lower nitrogen and sulphur and extractive content possessed quality fuel value and thereby were encouraged to be incorporated in fuelwood plantation establishment programs (A. leiocarpus, C. molle, C. arereh, and B. aegyptiaca). Lower energy fuelwood species should be allowed for environmental amelioration and carbon sequestration. However, bark contents should be removed for better heating and low ash production during combustion.

\section{Introduction}

Ten fuelwood species were selected for the study to investigate their inherent fuel quality in relation to nutrient element and chemical composition. The selection was done based on the demand by the inhabitants and overexploitation of fuelwood species in the northern part of Nigeria. This requires a serious need to address the mode of utilization of fuelwood species in the region, in that the region is faced with scarce vegetation, and the demand for fuelwood is always increasing due to population size, accessibility, and being cheaper in price compared with other sources of energy such as kerosene, electric devices, and LPGs. These are some of the reasons that the majority of the inhabitants prefer fuelwood as a source of energy, and the demand is so high to the extent that the woodland areas are turning to desert areas. Since the northern part of Nigeria is worst hit with the fuelwood scarcity, effort must be made to ensure fuelwood selection and create a fuelwood establishment program based on the fuel quality of the candidate trees. To 
achieve this, it is important to characterize fuelwood species in terms of combustion properties. The ultimate analysis (nutrient elements) plays a vital role in determining the fuel value of any woody biomass. This is as a result of the strong relationship between them and fuelwood properties. As a first guide therefore, the knowledge of the fuelwood properties will help to determine the inherent fuel energy potentials of some tree species.

Moreover, the trend in fuelwood demand increases on a daily basis, and many inhabitants depend on fuelwood for livelihood sustenance. This increases the quantity and intensity of fuelwood use, with a trend that does not appear to have the possibility of meeting the increasing demand in the future [1-5]. These projected future increases are perhaps because of the unpredictable changes in demographic and socioeconomic characteristics including the interplay between poverty, population increase, and other factors in this area coupled with the unpredictable fluctuations in the prices of domestic fossil fuels as kerosene, liquefied petroleum gas, and others [6]. Meanwhile, such an increase in fuelwood demand resulted in deforestation and sand dunce in the area. Therefore, it is important to evaluate chemical and elemental composition such as carbon, hydrogen, oxygen, sulphur, and nitrogen to determine the desirable and quality fuelwood species as a source of energy for both domestic and industrial uses [7]. Proper evaluation of these properties consequently enhances the overall wood biomass quality for heating and combustion efficiency [8].

The objectives of this study are to determine the nutrient elements and chemical composition required for quality fuelwood species. This plays a vital role in assessing fuel value of any woody biomass. As a first guide therefore, the knowledge of nutrient properties of fuelwood species will help determine the inherent fuel energy potentials of tree species.

\section{Materials and Methods}

The materials used for the study are ten (10) selected fuelwood species, digital weighing balance (Metriz 235), atomic absorption spectrometer, Spectrometer (UV 2150), oven, and platinum crucibles, and Wiley Mill.

2.1. Preparation of Wood Samples. Fuelwood species were identified 10-15 kilometers away from Damaturu, Yobe State, Nigeria, and harvested at $25 \mathrm{~cm}$ below and above diameter at breast height (Dbh), thereby making a total of $50 \mathrm{~cm}$ billets, and replicated three times. Each billet was wrapped with a black polythene bag to prevent moisture loss and transported to laboratory for investigations. In the laboratory, each billet was debarked. The bark portion and the wood were reduced separately to chip sizes of 10 to $30 \mathrm{~mm}$ with the aid of axe. The wood and bark chips were separately put into a container and carefully labeled. On each chip (wood and bark), the following samples were created using Nosek et al.'s method [9]:

$$
\begin{aligned}
& 100 \% \mathrm{~W}=\text { wood sample without bark } \\
& 5 \% \mathrm{~B}=\text { wood samples with } 5 \% \text { bark } \\
& 10 \% \mathrm{~B}=\text { wood samples with } 10 \% \text { bark } \\
& 100 \% \mathrm{~B}=\text { samples with } 100 \% \text { bark }
\end{aligned}
$$

Samples with $5 \%$ and $10 \%$ bark chips were created by mixing wood sample without bark with the bark sample. The proportion of $5 \%$ and $10 \%$ were employed due to the high numbers of fuelwood with bark contents in the range of 5\% to $10 \%$, based on the results of various works $[10,11]$. Each sample was air-dried at room temperature to constant moisture content before grinding to a fraction size less than $1 \mathrm{~mm}$ based on the American Standard for Testing and Material (ASTM) standard designation D2013-86 and thereafter subjected to nutrient element and chemical composition analyses.

2.2. Determination of Carbon, Hydrogen, and Oxygen ( $\mathrm{C}-\mathrm{H}-$ $O)$. The percentages of carbon, hydrogen, and oxygen were determined by

$$
\begin{aligned}
& \mathrm{C}=0.637 \mathrm{FC}+0.455 \mathrm{VM}, \\
& \mathrm{H}=0.052 \mathrm{FC}+0.62 \mathrm{VM}, \\
& \mathrm{O}=0.304 \mathrm{FC}+0.476 \mathrm{VM} .
\end{aligned}
$$

Sulphur (S) was obtained using

$$
\mathrm{S}=\mathrm{H}+\mathrm{C}+\mathrm{O}-100
$$

where $\mathrm{C}$ is the carbon content, $\mathrm{H}$ is the hydrogen content, $\mathrm{O}$ is the oxygen content, $\mathrm{FC}$ is the percentage of fixed carbon and VM is the volatile matter content (ASTM [12] and Bailey and Blankehorn [13]).

2.3. Nitrogen Determination. Nitrogen content was determined using Kjeldahl method adopted from Bremner [14]. Two grams of wood samples was heated with $100 \mathrm{ml}$ of distilled water and $20 \mathrm{ml}$ sulphuric acid at $337^{\circ} \mathrm{C}$ to liberate the reduced nitrogen as ammonium sulfate. One gram of potassium sulfate was added to increase the boiling point to $373^{\circ} \mathrm{C}$. The mixture heated at $373^{\circ} \mathrm{C}$ became very dark colored and gradually became clear and colorless. Then, the solution was distilled with a small quantity of sodium hydroxide, which converted ammonium to ammonia. The amount of ammonia and nitrogen present in the sample was determined by back titration. The end of the condenser was then dipped into a solution of boric acid. Ammonia was reacted with sulphuric acid and titrated with sodium carbonate solution and methyl orange $\mathrm{pH}$ indicator at 4.65 for the titration [14]. The percent of nitrogen was calculated using 


$$
\operatorname{nitrogen}(\%)=\frac{(\mathrm{ml} \text { standard acid }-\mathrm{ml} \text { blank }) \times(N \text { of acid } \times 1.4007)}{\text { weight of sample in } \mathrm{g}},
$$

where ml blank is milliliters of base needed to back-titrate a reagent blank if standard acid is the receiving solution or milliliters of standard acid needed to titrate a reagent blank if boric acid is the receiving solution, $N$ is the normality of acid, and 1.4007 is the milliequivalent weight of nitrogen $\times 100 \%$.

\subsection{Determination of Chemical Content}

2.4.1. Lignin Content. Lignin content was determined using TAPPI [15], where $100 \mathrm{mg}$ of the wood sample was weighed and placed into a glass beaker with a volume of at least $150 \mathrm{ml}$, and $1.0 \mathrm{ml}$ of $72 \%$ sulphuric acid was added to the beaker with a pipette. The contents in the beaker were stirred with a glass rod until the samples began to dissolve. The beakers were placed in a $30^{\circ} \mathrm{C}$ water bath for $1 \mathrm{~h}$ and stirred occasionally. Then, $28.0 \mathrm{ml}$ of water was added and the beakers were covered with aluminum foil and placed in an autoclave at $120^{\circ} \mathrm{C}$ for $1 \mathrm{~h}$. The beakers and their contents were allowed to cool to $80^{\circ} \mathrm{C}$ [16].

The contents of the beakers were filtered while still hot through a single or double preweighed glass fiber filter. Then, the filtrate was transferred to a separate beaker (this filtrate is used for the determination of acid-soluble lignin). The retained residues were washed with hot water until acid-free (checked with $\mathrm{pH}$-indicator paper). The filters with residues from the filter container were removed carefully and allowed to dry overnight at $105^{\circ} \mathrm{C}$ and cooled in desiccators and the decrease was weighed (i.e., the acid-insoluble residue).

The content of acid-soluble lignin was determined in the first filtrate by spectrophotometer at $205 \mathrm{~nm}$. The filtrate was diluted until absorption was in the range 0.2-0.7 AU [16]:

$$
\text { acid }- \text { insoluble residue }(\mathrm{AIR})=\frac{m}{M} \times 1000 \mathrm{mg} / \mathrm{g},
$$

where $m$ is the weight increase (the residue after drying) in grams and $M$ is the oven-dry weight of sample $(100 \%$ dry matter) before acid hydrolysis/suspension, in grams:

$$
\text { acid }- \text { soluble lignin }(\mathrm{ASL})=\frac{A \times D \times V}{a \times b \times M} \times 1000 \mathrm{mg} / \mathrm{g} \text {, }
$$

where $A$ is the absorption at $205 \mathrm{~nm}, D$ is the dilution factor, $V$ is the volume of the filtrate, $a$ is the extinction coefficient of lignin in grams per centimeter, $b$ is the cuvette path length, in centimeter, and $M$ is the weight of sample (as 100\% dry matter) before acid hydrolysis/suspension in grams:

$$
\text { total lignin content }=\text { AIR }+ \text { ASL } \text {. }
$$

2.4.2. Extractive Content. Extractive content was determined using dichloromethane solvent extraction method (TAPPI [15]). Five grams of wood sample was subjected to $105^{\circ} \mathrm{C}$ oven-drying for 12 hours and then removed and allowed to cool in desiccators and weighed to the nearest $0.1 \mathrm{mg}$. Then, the sample was poured into a beaker and $50 \mathrm{ml}$ of dichloromethane was added. Then, the beaker was covered with nylon to prevent the solvent from escaping and allowed to dissolve overnight. Then, the extract was filtrated and the solvent was allowed to escape completely. Then, the extract was oven-dried and allowed to cooled and weighed. The percentage extractive was determined using

$$
\text { extractive }(\%)=\frac{\text { weight of flask plus extractive }- \text { weight of flask }}{\text { ODW sample }} \times 100 \%
$$

where ODW is the oven-dried weight.

\section{Statistical Analysis}

A two-factor factorial experiment in a completely randomized design was employed for this study:

$$
Y_{i j k}=\mu+A_{i}+B_{j}+(A B)_{i j}+E_{i j k} \text {, }
$$

where $Y_{i j}$ is the individual observation, $\mu$ is the general mean, $A_{i}$ is the effect of variation in tree species (factor $A$ ), $B_{j}$ is the effect of variation in bark content (factor $\mathrm{B}$ ), $A B_{i j}$ is the effect of interaction between factors $A$ and $B$, and $E_{i j k}$ is the experimental error.

\section{Results and Discussion}

The nutrient elements are those elements that make up the various components of wood (cellulose, hemicelluloses, lignin, and others) which contributes mainly to the heating value of fuelwood species.

4.1. Carbon Content. The results of this study reveal that the average carbon content obtained for all the selected trees in this study ranges from $49.54 \%$ in A sieberiana to $50.98 \%$ obtained in A. leiocarpus (Table 1). This range is similar to those recorded for some indigenous tree species by Deka et al. [17] but higher than those reported for some hard and softwood species by Telmo and Lousada [18]. Meanwhile, 
TABLE 1: Effect of bark inclusion on the carbon contents (\%) of selected fuelwood species.

\begin{tabular}{|c|c|c|c|c|c|}
\hline \multirow{2}{*}{ Tree species } & \multicolumn{5}{|c|}{ Carbon } \\
\hline & $100 \% \mathrm{~W}$ & $5 \% \mathrm{~B}$ & $10 \% \mathrm{~B}$ & $100 \% \mathrm{~B}$ & Mean \\
\hline A. leiocarpus & $50.99^{\mathrm{a}}$ & $50.84^{\mathrm{a}}$ & $50.13^{\mathrm{a}}$ & $48.71^{\mathrm{b}}$ & $50.98^{\mathrm{a}}$ \\
\hline C. arereh & $53.45^{\mathrm{a}}$ & $51.31^{\mathrm{b}}$ & $50.58^{\mathrm{b}}$ & $48.60^{\mathrm{c}}$ & $50.16^{\mathrm{ab}}$ \\
\hline B. aegyptiaca & $51.24^{\mathrm{a}}$ & $50.59^{\mathrm{ab}}$ & $49.26^{\mathrm{bc}}$ & $47.94^{\mathrm{c}}$ & $49.76^{\mathrm{b}}$ \\
\hline C. molle & $50.52^{\mathrm{a}}$ & $49.78^{\mathrm{a}}$ & $49.40^{\mathrm{a}}$ & $49.34^{\mathrm{a}}$ & $49.76^{\mathrm{b}}$ \\
\hline T. mollis & $50.54^{\mathrm{a}}$ & $50.38^{\mathrm{a}}$ & $49.63^{\mathrm{ab}}$ & $48.29^{\mathrm{b}}$ & $49.72^{b}$ \\
\hline T. indica & $50.30^{\mathrm{a}}$ & $50.11^{\mathrm{a}}$ & $49.57^{\mathrm{a}}$ & $48.85^{\mathrm{a}}$ & $49.71^{\mathrm{b}}$ \\
\hline S. birrea & $50.67^{\mathrm{c}}$ & $50.36^{\mathrm{ab}}$ & $49.83^{\mathrm{b}}$ & $47.94^{\mathrm{c}}$ & $49.58^{\mathrm{b}}$ \\
\hline C. lamprocarpum & $50.49^{\mathrm{a}}$ & $50.12^{\mathrm{a}}$ & $49.79^{\mathrm{a}}$ & $48.19^{\mathrm{b}}$ & $49.65^{\mathrm{b}}$ \\
\hline P. reticulatum & $50.92^{\mathrm{a}}$ & $50.07^{\mathrm{ab}}$ & $49.41^{\mathrm{b}}$ & $47.93^{c}$ & $49.58^{\mathrm{b}}$ \\
\hline A. sieberiana & $50.46^{\mathrm{a}}$ & $50.02^{\mathrm{a}}$ & $49.27^{\mathrm{a}}$ & $48.42^{\mathrm{a}}$ & $49.54^{\mathrm{b}}$ \\
\hline
\end{tabular}

$\mathbf{W}$ is the wood, and $\mathbf{B}$ is the bark. Values with the same alphabets within the same rows are not significantly different, and values with the same alphabets in the mean column are not significantly different using Duncan multiple range test at $\alpha=0.05$.

the addition of $5 \%$ and $10 \%$ bark fraction reduces the carbon content of wood by $1.25 \%$ and $2.74 \%$, respectively (Figure 1 ). However, the carbon content of $100 \%$ bark is about $12 \%$ lower compared with wood without bark. This is similar to what was reported for some indigenous fuelwood species by Deka et al. [17].

4.2. Hydrogen Content. The hydrogen content ranges from $3.99 \%$ in $P$. reticulatum to $4.66 \%$ obtained in $C$. arereh (Table 2). The value was similar to those reported for some tree species by Telmo and Lousada [18] but lower than what was recorded for some indigenous tree species by Deka et al. [17]. Meanwhile, among the fuel material types, wood contained $1.09 \%$ higher hydrogen content than the isolated bark. Similarly, the addition of bark to the tune of $5 \%$ and $10 \%$ progressively lowered the hydrogen content of the fuelwood species (Figure 1). The rate, however, varies across the tree species. Some authors have also reported lower hydrogen content in isolated bark compared with wood without bark [17, 19, 20].

4.3. Nitrogen Content. Nitrogen content ranged from $0.31 \%$ in A. leiocarpus to $1.00 \%$ in A. sieberiana (Table 2). Among the fuel materials used, the isolated bark contained approximately $0.45 \%$ nitrogen content compared with wood without bark. Similarly, the inclusion of bark fraction to the wood fuel in the amount of 5\% and 10\% alternately increased the nitrogen content of the fuel materials (Figure 1). The value recorded in this study is similar to those recorded for some tree species by Alvarez-Alvarez et al. [21].

4.4. Oxygen Content. The average oxygen content in the selected trees ranges from $40.22 \%$ in $P$. reticulatum to $43.16 \%$ in $A$. leiocarpus (Table 3 ). The values recorded were similar to those reported for some tree species by Telmo and Lousada [18] and Deka et al. [17]. However, unlike the other mineral elements, the oxygen content did not follow a particular order with addition of bark fraction to wood. For example, while oxygen content in the wood fuel decreases with addition of bark fraction to the tune of $5 \%$ and $10 \%$ alternately in A. leiocarpus, C. arereh, and C. mole, it increases in fuel stock obtained from T. mollis, T. indica, $S$. birrea, C. lamprocarpum, $P$. reticulatum, and A. sieberiana. However, despite this trend, the oxygen content is lower in the bark than in wood without bark except in fuel stock obtained from $P$. reticulatum and $A$. sieberiana, which had higher oxygen content in the bark (Table 3). This is similar to what was reported by Telmo and Lousada [18]. However, in a study carried out by Demirbas and Arin [22] on Spruce and Beech wood, the trunk wood had marginal higher oxygen content than the bark. The oxygen content has no relation with heating value of fuelwood species in this study, which also corresponds with what was reported by Sheng and Azevedo [23] and Saidur [24].

4.5. Sulphur Content. One of the effects of burning biomass for energy of most concern is the atmospheric emission of sulphur dioxide $\left(\mathrm{SO}_{2}\right)$, different nitrogen oxides, and to a lesser extent ammonia $\left(\mathrm{NH}_{3}\right)$, which directly or indirectly affects natural ecosystems. The sulphur content in all the selected trees was less than one percent. The variation in sulphur contents ranges from $0.24 \%$ in C. arereh to $0.93 \%$ in A. sieberiana (Table 4 ). The values obtained in this study were similar to those recorded for some tree species by Saarela et al. [25], but higher than the range of $0.001 \%$ to $0.06 \%$ obtained in some tree species by Telmo and Lousada [18]. Meanwhile, the bark portion contains more sulphur than its corresponding wood. Similarly, addition of bark fraction to the wood fuel stock significantly increased the sulphur content (Table 4 and Figure 1). The rate of increase, however, varies across species. Similarly, increase in sulphur content in the bark compared with wood without bark of some tree has been reported by García et al. [26] and Wang et al. [27]. The $\mathrm{SO}_{2}$ emissions are not significant for wood combustion because of the low sulphur content but can be relevant for agricultural residues, grasses, and straw [26].

\subsection{Chemical Compounds of the Ten Selected Fuelwood Species}

4.6.1. Lignin Content. Lignin is a complex polyphenolic material arising from enzymatic dehydrogenative polymerization of 


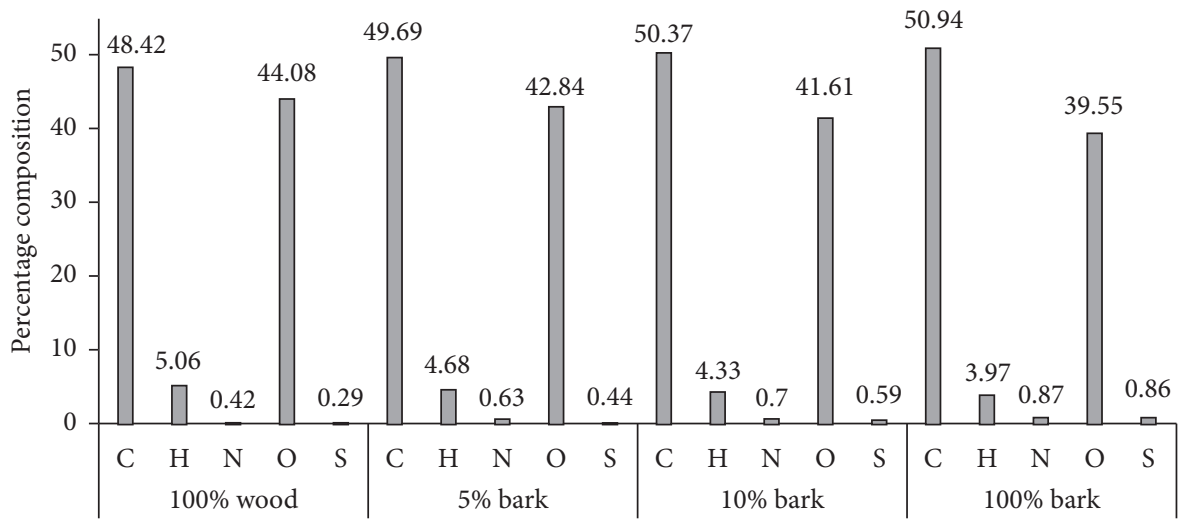

FIGURE 1: Average elemental composition of the fuelwood materials.

TABLE 2: Effect of bark inclusion on hydrogen and nitrogen contents (\%) of selected fuelwood species.

\begin{tabular}{|c|c|c|c|c|c|c|c|c|c|c|}
\hline \multirow{2}{*}{ Tree species } & \multicolumn{5}{|c|}{ Hydrogen } & \multicolumn{5}{|c|}{ Nitrogen } \\
\hline & $100 \% \mathrm{~W}$ & $5 \% \mathrm{~B}$ & $10 \% \mathrm{~B}$ & $100 \% \mathrm{~B}$ & Mean & $100 \% \mathrm{~W}$ & $5 \% \mathrm{~B}$ & $10 \% \mathrm{~B}$ & $100 \% \mathrm{~B}$ & Mean \\
\hline A. leiocarpus & $5.43^{\mathrm{a}}$ & $4.79^{\mathrm{b}}$ & $4.54^{\mathrm{c}}$ & $4.37^{\mathrm{d}}$ & $4.78^{\mathrm{a}}$ & $0.22^{\mathrm{b}}$ & $0.26^{\mathrm{ab}}$ & $0.29^{\mathrm{ab}}$ & $0.47^{\mathrm{a}}$ & $0.31^{\mathrm{f}}$ \\
\hline C. arereh & $5.40^{\mathrm{a}}$ & $4.95^{\mathrm{b}}$ & $4.66^{c}$ & $4.11^{\mathrm{d}}$ & $4.78^{\mathrm{a}}$ & $0.22^{\mathrm{C}}$ & $0.37^{\mathrm{b}}$ & $0.38^{\mathrm{b}}$ & $0.55^{\mathrm{a}}$ & $0.38^{\mathrm{f}}$ \\
\hline B. aegyptiaca & $5.41^{\mathrm{a}}$ & $4.93^{\mathrm{b}}$ & $4.25^{\mathrm{c}}$ & $3.73^{\mathrm{d}}$ & $4.58^{\mathrm{ab}}$ & $0.29^{c}$ & $0.39^{\mathrm{b}}$ & $0.40^{\mathrm{ab}}$ & $0.42^{\mathrm{a}}$ & $0.38^{\mathrm{f}}$ \\
\hline C. molle & $4.98^{\mathrm{a}}$ & $4.59^{\mathrm{ab}}$ & $4.43^{\mathrm{b}}$ & $4.33^{\mathrm{b}}$ & $4.58^{\mathrm{ab}}$ & $0.21^{\mathrm{c}}$ & $0.49^{\mathrm{b}}$ & $0.72^{\mathrm{a}}$ & $0.76^{\mathrm{a}}$ & $0.55^{\mathrm{de}}$ \\
\hline T. mollis & $4.95^{\mathrm{a}}$ & $4.67^{\mathrm{ab}}$ & $4.48^{\mathrm{ab}}$ & $4.15^{\mathrm{b}}$ & $4.56^{\mathrm{ab}}$ & $0.46^{\mathrm{a}}$ & $0.50^{\mathrm{a}}$ & $0.49^{\mathrm{a}}$ & $0.60^{\mathrm{a}}$ & $0.51^{\mathrm{e}}$ \\
\hline T. indica & $4.62^{\mathrm{a}}$ & $4.79^{\mathrm{a}}$ & $4.41^{\mathrm{a}}$ & $4.23^{\mathrm{a}}$ & $4.51^{\mathrm{ab}}$ & $0.08^{\mathrm{d}}$ & $0.46^{\mathrm{c}}$ & $0.76^{\mathrm{b}}$ & $1.15^{\mathrm{a}}$ & $0.61^{\mathrm{cd}}$ \\
\hline S. birrea & $5.24^{\mathrm{a}}$ & $4.76^{\mathrm{b}}$ & $4.40^{\mathrm{c}}$ & $3.58^{\mathrm{d}}$ & $4.49^{\mathrm{b}}$ & $0.19^{c}$ & $0.71^{\mathrm{b}}$ & $0.78^{\mathrm{b}}$ & $0.96^{\mathrm{a}}$ & $0.66^{\mathrm{c}}$ \\
\hline C. lamprocarpum & $4.72^{\mathrm{a}}$ & $4.67^{\mathrm{a}}$ & $4.38^{\mathrm{ab}}$ & $4.11^{\mathrm{a}}$ & $4.47^{\mathrm{b}}$ & $0.78^{\mathrm{c}}$ & $0.94^{\mathrm{b}}$ & $0.96^{\mathrm{b}}$ & $1.06^{\mathrm{a}}$ & $0.94^{\mathrm{b}}$ \\
\hline P. reticulatum & $5.17^{\mathrm{a}}$ & $4.28^{\mathrm{b}}$ & $3.51^{\mathrm{c}}$ & $3.02^{\mathrm{d}}$ & $3.99^{c}$ & $1.08^{\mathrm{b}}$ & $1.22^{\mathrm{a}}$ & $1.26^{\mathrm{a}}$ & $1.29^{\mathrm{a}}$ & $1.21^{\mathrm{a}}$ \\
\hline A. sieberiana & $1.69^{\mathrm{a}}$ & $4.37^{\mathrm{b}}$ & $4.21^{\mathrm{bc}}$ & $4.11^{\mathrm{c}}$ & $4.34^{\mathrm{b}}$ & $0.70^{\mathrm{c}}$ & $0.93^{\mathrm{b}}$ & $0.95^{\mathrm{b}}$ & $1.45^{\mathrm{a}}$ & $1.00^{\mathrm{b}}$ \\
\hline
\end{tabular}

$\mathbf{W}$ is the wood, and $\mathbf{B}$ is the bark. Values with the same alphabets within the same rows are not significantly different, and values with the same alphabets in the mean column are not significantly different using Duncan multiple range test at $\alpha=0.05$.

TABLE 3: Effect of bark inclusion on the oxygen content (\%) of the selected fuelwood species.

\begin{tabular}{lccccc}
\hline & \multicolumn{5}{c}{ Oxygen } \\
Tree species & $100 \%$ & $5 \%$ & $10 \%$ & $100 \%$ & Mean \\
& wood & bark & bark & bark & \\
\hline A. leiocarpus & $45.26^{\mathrm{a}}$ & $43.28^{\mathrm{b}}$ & $42.49^{\mathrm{c}}$ & $41.61^{\mathrm{d}}$ & $43.16^{\mathrm{a}}$ \\
C. arereh & $45.12^{\mathrm{a}}$ & $43.80^{\mathrm{b}}$ & $42.76^{\mathrm{c}}$ & $40.73^{\mathrm{d}}$ & $43.10^{\mathrm{a}}$ \\
B. aegyptiaca & $45.18^{\mathrm{a}}$ & $43.62^{\mathrm{a}}$ & $41.48^{\mathrm{b}}$ & $39.02^{\mathrm{c}}$ & $42.33^{\mathrm{ab}}$ \\
C. molle & $43.90^{\mathrm{a}}$ & $42.65^{\mathrm{a}}$ & $41.62^{\mathrm{b}}$ & $40.99^{\mathrm{b}}$ & $42.29^{\mathrm{ab}}$ \\
T. mollis & $42.17^{\mathrm{a}}$ & $42.78^{\mathrm{a}}$ & $43.72^{\mathrm{a}}$ & $39.81^{\mathrm{b}}$ & $42.12^{\mathrm{b}}$ \\
T. indica & $42.70^{\mathrm{ab}}$ & $43.12^{\mathrm{a}}$ & $41.69^{\mathrm{b}}$ & $40.32^{\mathrm{c}}$ & $41.96^{\mathrm{b}}$ \\
S. birrea & $39.49^{\mathrm{b}}$ & $41.73^{\mathrm{a}}$ & $42.69^{\mathrm{a}}$ & $43.08^{\mathrm{a}}$ & $41.75^{\mathrm{b}}$ \\
C. lamprocarpum & $41.85^{\mathrm{b}}$ & $43.02^{\mathrm{a}}$ & $44.54^{\mathrm{a}}$ & $38.11^{\mathrm{c}}$ & $41.88^{\mathrm{b}}$ \\
P. reticulatum & $35.71^{\mathrm{d}}$ & $39.16^{\mathrm{c}}$ & $41.62^{\mathrm{b}}$ & $44.39^{\mathrm{a}}$ & $40.22^{\mathrm{c}}$ \\
A. sieberiana & $41.16^{\mathrm{b}}$ & $41.83^{\mathrm{b}}$ & $42.93^{\mathrm{a}}$ & $39.71^{\mathrm{c}}$ & $41.41^{\mathrm{b}}$ \\
\hline Valu with & & & & &
\end{tabular}

Values with the same alphabets within the same rows are not significantly different, and values with the same alphabets in the mean column are not significantly different using Duncan multiple range test at $\alpha=0.05$.

the phenylpropene units. It plays a vital role in the combustion process as a result of reduction state in chemical makeup of the wood both on the molecular and atomic levels [7]. The result of this study shows that the average lignin content obtained for all the selected trees in this study was quite high. The value ranged
TABLE 4: Effect of bark inclusion on the sulphur content (\%) of the selected fuelwood species.

\begin{tabular}{|c|c|c|c|c|c|}
\hline \multirow[b]{2}{*}{ Tree species } & \multicolumn{5}{|c|}{ Sulphur } \\
\hline & $\begin{array}{l}100 \% \\
\text { wood }\end{array}$ & $\begin{array}{c}5 \% \\
\text { bark }\end{array}$ & $\begin{array}{l}10 \% \\
\text { bark }\end{array}$ & $\begin{array}{l}100 \% \\
\text { bark }\end{array}$ & Mean \\
\hline A. leiocarpus & $0.19^{\mathrm{b}}$ & $0.22^{\mathrm{ab}}$ & $0.23^{\mathrm{ab}}$ & $0.26^{\mathrm{a}}$ & $0.33^{\mathrm{d}}$ \\
\hline C. arereh & $0.07^{\mathrm{b}}$ & $0.28^{\mathrm{a}}$ & $0.29^{\mathrm{a}}$ & $0.33^{\mathrm{a}}$ & $0.24^{\mathrm{d}}$ \\
\hline B. aegyptiaca & $0.06^{\mathrm{b}}$ & $0.10^{\mathrm{b}}$ & $0.11^{\mathrm{b}}$ & $0.95^{\mathrm{b}}$ & $0.31^{\mathrm{cc}}$ \\
\hline C. molle & $0.37^{\mathrm{b}}$ & $0.37^{\mathrm{b}}$ & $0.37^{\mathrm{b}}$ & $0.41^{\mathrm{a}}$ & $0.38^{\mathrm{c}}$ \\
\hline T. mollis & $0.06^{\mathrm{b}}$ & $0.15^{\mathrm{b}}$ & $1.11^{\mathrm{a}}$ & $1.14^{\mathrm{a}}$ & $0.62^{\mathrm{b}}$ \\
\hline T. indica & $0.11^{\mathrm{b}}$ & $0.17^{\mathrm{b}}$ & $1.09^{\mathrm{a}}$ & $1.14^{\mathrm{a}}$ & $0.63^{\mathrm{b}}$ \\
\hline S. birrea & $0.18^{\mathrm{c}}$ & $0.22^{c}$ & $0.98^{\mathrm{b}}$ & $1.16^{\mathrm{a}}$ & $0.64^{\mathrm{b}}$ \\
\hline C. lamprocarpum & $0.22^{\mathrm{b}}$ & $0.23^{\mathrm{b}}$ & $0.91^{\mathrm{a}}$ & $1.25^{\mathrm{a}}$ & $0.65^{\mathrm{b}}$ \\
\hline P. reticulatum & $0.81^{\mathrm{b}}$ & $0.82^{\mathrm{b}}$ & $0.82^{\mathrm{b}}$ & $0.995^{\mathrm{a}}$ & $0.85^{\mathrm{a}}$ \\
\hline A. sieberiana & $0.85^{\mathrm{b}}$ & $0.86^{\mathrm{b}}$ & $0.98^{\mathrm{a}}$ & $1.01^{\mathrm{a}}$ & $0.93^{\mathrm{a}}$ \\
\hline
\end{tabular}

Values with the same alphabets within the same rows are not significantly different, and values with the same alphabets in the mean column are not significantly different using Duncan multiple range test at $\alpha=0.05$.

from $10.68 \%$ in A. sieberiana to $25.39 \%$ in A. leiocarpus (Table 5). The values obtained are similar to those recorded for some selected wood species by Miller [28], Nasser and Aref [29], and Deka et al. [17]. 
TABLE 5: Effect of bark inclusion on the lignin content (\%) of selected fuelwood species.

\begin{tabular}{|c|c|c|c|c|c|}
\hline \multirow{2}{*}{ Tree species } & \multicolumn{5}{|c|}{ Fuel material composition } \\
\hline & $100 \%$ wood & $5 \%$ bark & $10 \%$ bark & $100 \%$ bark & Mean \\
\hline Anogeisus leiocarpus & $33.00^{\mathrm{a}}$ & $25.64^{\mathrm{b}}$ & $23.02^{c}$ & $18.88^{\mathrm{d}}$ & $25.39^{\mathrm{a}}$ \\
\hline Caccia arereh & $28.07^{\mathrm{a}}$ & $25.87^{\mathrm{b}}$ & $24.67^{\mathrm{c}}$ & $22.24^{\mathrm{d}}$ & $25.21^{\mathrm{a}}$ \\
\hline Balanites aegyptiaca & $28.00^{\mathrm{a}}$ & $25.54^{\mathrm{b}}$ & $24.33^{\mathrm{c}}$ & $21.75^{\mathrm{d}}$ & $24.90^{\mathrm{a}}$ \\
\hline Combretum molle & $27.04^{\mathrm{a}}$ & $24.96^{\mathrm{b}}$ & $23.47^{\mathrm{c}}$ & $21.24^{\mathrm{d}}$ & $24.18^{\mathrm{b}}$ \\
\hline Terminalia mollis & $27.06^{\mathrm{a}}$ & $25.78^{\mathrm{b}}$ & $25.08^{\mathrm{c}}$ & $14.33^{\mathrm{d}}$ & $23.06^{\mathrm{c}}$ \\
\hline Tarmarindus indica & $15.12^{\mathrm{a}}$ & $13.45^{\mathrm{b}}$ & $11.74^{\mathrm{c}}$ & $10.15^{\mathrm{d}}$ & $12.61^{\mathrm{d}}$ \\
\hline Sclerocarya birrea & $15.00^{\mathrm{a}}$ & $12.84^{\mathrm{b}}$ & $11.62^{\mathrm{c}}$ & $10.11^{\mathrm{d}}$ & $12.39^{\mathrm{d}}$ \\
\hline Combretum lamprocarpum & $14.11^{\mathrm{a}}$ & $12.61^{\mathrm{b}}$ & $11.62^{\mathrm{c}}$ & $10.31^{\mathrm{d}}$ & $12.16^{\mathrm{d}}$ \\
\hline Piliostigma reticulatum & $12.49^{\mathrm{a}}$ & $11.50^{\mathrm{b}}$ & $10.67^{\mathrm{c}}$ & $9.34^{\mathrm{d}}$ & $11.00^{\mathrm{e}}$ \\
\hline Acacia sieberiana & $13.36^{\mathrm{a}}$ & $10.90^{\mathrm{b}}$ & $9.89^{c}$ & $8.58^{\mathrm{d}}$ & $10.68^{\mathrm{e}}$ \\
\hline
\end{tabular}

Values with the same alphabets within the same species and among species in mean column are not significantly different using Duncan multiple range test at $\alpha=0.05$.

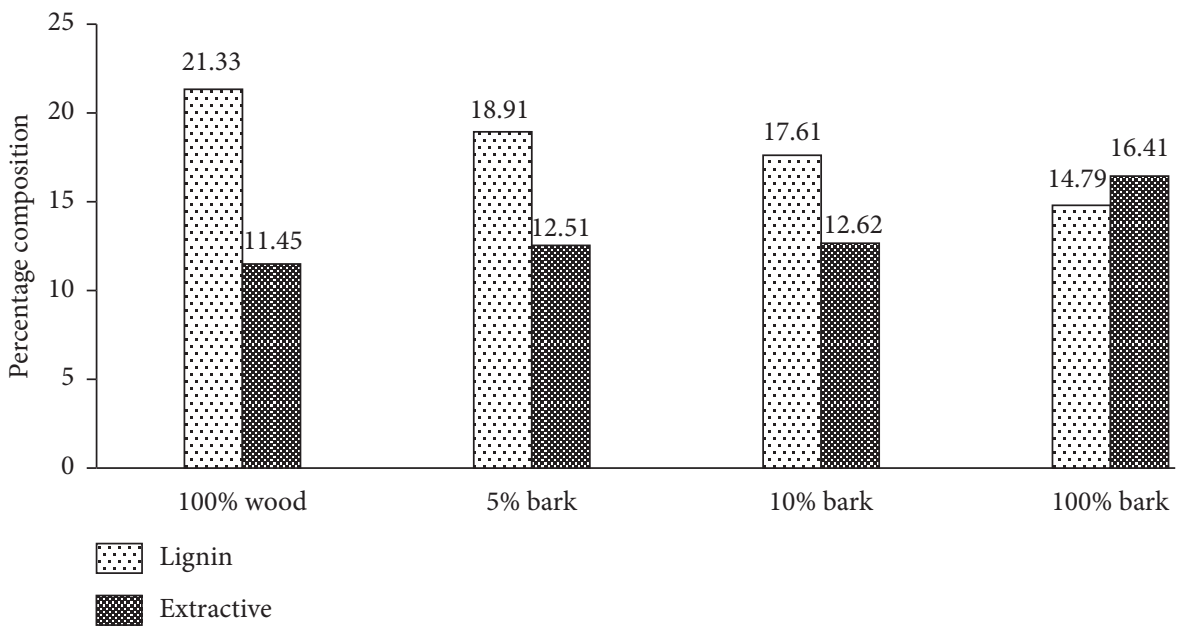

FIgURE 2: Average lignin and extractive content (\%) of the fuel materials from the selected fuelwood species.

Meanwhile, lignin content in all the selected species was found to be significantly higher in wood than the respective barks. Averagely, lignin content was found to be $6.54 \%$ higher in wood than the bark. Similarly, the inclusion of 5\% and $10 \%$ bark fractions in the wood fuel material lowers the lignin content by $2.42 \%$ and $4.24 \%$, respectively (Figure 2 ). However, the degree of variation was not constant across species (Table 5). Similarly, Deka et al. [17] reported higher lignin content in some indigenous fuelwood species compared with bark. In general, lignin content plays a vital role in the combustion process as a result of reduction state in chemical makeup of the wood both in molecular and atomic levels. The lignin content of wood significantly influences the heating value of wood. The higher the lignin content, the higher the heating value of the fuelwood species.

4.6.2. Extractive Content. Extractives are nonstructural and low molecular weight compound present in wood. They include fats, waxes, alkaloid, protein, gum, resins, starch, glycoside, and essential oils, most of which are readily soluble in neutral organic solvents or cold water. The diverse nature and composition of extractives, and the quantities determines the heating value of biofuel for energy purpose. In this study, the average extractive content ranges from $7.31 \%$ in A. leiocarpus to $19.33 \%$ in P. reticulatum (Table 6). The values obtained in this study are similar to those recorded for some Acacia species by Nasser and Aref [29]. Meanwhile, among the fuel material types, isolated bark contained approximately $5.0 \%$ extractive content more than wood without bark (Figure 2). Similarly, the addition of bark fraction at $5 \%$ and $10 \%$, respectively, increases the extractive content of the fuel material type by $1.06 \%$ and $1.17 \%$ (Figure 2). However, the trend of increment in extractive content with bark inclusion onto the wood fuel differs among tree species (Table 6). Demirbas and Sims [30] and Deka et al. [17] reported a similar trend of increment in extractive content for some wood species. Many studies have shown the influence of extractive content on combustion properties of fuelwood $[31,32]$ and concluded that extractive content significantly influences the heating values of biofuel. However, more extractives are usually found in the bark of wood, and therefore it increases the heating value of fuelwood. 
TABLE 6: Effect of bark inclusion on the extractive content (\%) of selected fuelwood species.

\begin{tabular}{|c|c|c|c|c|c|}
\hline \multirow{2}{*}{ Tree species } & \multicolumn{5}{|c|}{ Fuel material composition } \\
\hline & $100 \%$ wood & $5 \%$ bark & $10 \%$ bark & $100 \%$ bark & Mean \\
\hline Anogeisus leiocarpus & $6.14^{\mathrm{b}}$ & $6.18^{\mathrm{b}}$ & $6.68^{\mathrm{b}}$ & $10.23^{\mathrm{a}}$ & $7.31^{\mathrm{g}}$ \\
\hline Caccia arereh & $8.58^{\mathrm{b}}$ & $11.01^{\mathrm{a}}$ & $11.45^{\mathrm{a}}$ & $11.66^{\mathrm{a}}$ & $10.68^{\mathrm{e}}$ \\
\hline Balanites aegyptiaca & $6.05^{\mathrm{c}}$ & $8.98^{\mathrm{b}}$ & $9.07^{\mathrm{b}}$ & $13.28^{\mathrm{a}}$ & $9.34^{\mathrm{f}}$ \\
\hline Combretum molle & $8.75^{\mathrm{b}}$ & $9.57^{\mathrm{b}}$ & $9.61^{\mathrm{b}}$ & $16.37^{\mathrm{a}}$ & $11.07^{\mathrm{e}}$ \\
\hline Terminalia mollis & $11.53^{\mathrm{d}}$ & $11.93^{\mathrm{c}}$ & $12.50^{\mathrm{b}}$ & $15.13^{\mathrm{a}}$ & $12.78^{\mathrm{d}}$ \\
\hline Tarmarindus indica & $13.83^{\mathrm{c}}$ & $14.83^{\mathrm{b}}$ & $14.90^{\mathrm{ab}}$ & $15.40^{\mathrm{a}}$ & $14.74^{\mathrm{C}}$ \\
\hline Sclerocarya birrea & $9.99^{c}$ & $10.90^{\mathrm{b}}$ & $11.29^{\mathrm{b}}$ & $29.96^{\mathrm{a}}$ & $15.54^{\mathrm{C}}$ \\
\hline Combretum lamprocarpum & $14.73^{\mathrm{b}}$ & $14.77^{\mathrm{b}}$ & $15.40^{\mathrm{a}}$ & $15.47^{\mathrm{a}}$ & $15.09^{\mathrm{c}}$ \\
\hline Piliostigma reticulatum & $19.03^{\mathrm{a}}$ & $19.13^{\mathrm{a}}$ & $19.53^{\mathrm{a}}$ & $19.63^{\mathrm{a}}$ & $19.33^{\mathrm{a}}$ \\
\hline Acacia sieberiana & $15.83^{\mathrm{b}}$ & $16.77^{\mathrm{a}}$ & $16.80^{\mathrm{a}}$ & $16.93^{\mathrm{a}}$ & $16.58^{\mathrm{b}}$ \\
\hline
\end{tabular}

Values with the same alphabets within the same species and among species in mean column are not significantly different using Duncan multiple range test at $\alpha=0.05$.

\section{Conclusion}

The nutrient element and chemical composition of fuelwood species have significant influences on the energy value of woody biomass. Carbon, hydrogen, and lignin contents were shown to be the main heat-producing elements and directly contribute to the heating value of fuelwood species with low nitrogen, sulphur, and extractive content. Meanwhile, higher carbon, hydrogen, and lignin contents were observed in A. leiocarpus, C. arereh, C. molle, and B. aegyptiaca coupled with lower nitrogen, sulphur, and extractive content, respectively, which possessed high energy value. Similarly, lignin content contributes significantly to the heating value of woody biomass in reduction stage (resin < lignin < cellulose). Therefore, the higher the lignin content, the greater the energy value of fuelwood species. Meanwhile, nitrogen and sulphur contents in fuelwood species usually pollute the environment by producing oxides of nitrogen and sulphur during combustion and directly or indirectly contribute to climate change. Therefore, fuelwood species with high nitrogen and sulphur content found in $A$. sieberiana, S. birrea, and C. lamprocarpum, respectively, coupled with low energy values are discouraged to be used for energy value; rather, they should be allowed for environmental amelioration. Therefore, A. leiocarpus, C. arereh, C. molle, and B. aegyptiaca are encouraged to be incorporated in a fuelwood plantation establishment program and used in both domestic and commercial cooking and heating.

Meanwhile, inclusion of bark content in the amount of $5 \%$ and $10 \%$ significantly influenced the energy value of the selected fuelwood species by reducing the heating value and increasing ash and smoke during combustion. Therefore, bark content of fuelwood species for use as a source of energy should be removed for better heating value.

\section{Data Availability}

No data were used to support this study.

\section{Conflicts of Interest}

The authors declare that there are no conflicts of interest regarding the publication of this manuscript.

\section{References}

[1] A. A. Erakhrumen, "Wood energy value as a factor of species selectivity in agroforestry in selected local government areas of oyo state, Nigeria," M.Sc. Dissertation, p. 87, Department of Forest Resources Mgt, University of Ibadan, Ibadan, Nigeria, 2005.

[2] A. A. Erakhrumen, "Overview of various biomass energy conversion routes," American-Eurasian Journal of Agricultural \& Environmental Sciences, vol. 2, no. 6, pp. 662-671, 2007.

[3] A. A. Erakhrumen, "Influence of specific gravity on wood species selection for agroforestry in some local government areas of oyo state,Nigeria," Afr. J. Agric. Res.vol. 3, no. 2, pp. 134-139, 2008.

[4] Food and Agriculture Organization, "The role of woodfuel in Africa," in Proceeding of the High Level Regional Meeting on Energy and Sustainable Development, Food and Agriculture Organization of the United Nations, Nairobi, Kenya, pp. 99-101, January 2001.

[5] Food and Agriculture Organization, State of the World's Forest, United Nation, Rome, Italy, 2007.

[6] A. A. Erakhrumen, "Implications of global economic recession/volatility in petroleum products' price, demand, and supplyon fuelwood consumption and mangrove forests' survival in the Niger-delta region. The global economic crisis and sustainable renewable natural resources management," Edited by L. Popoola, F. O. Idumah, V. A. J. Adekunle, and I. O. Azeez, Eds., in Proceedings of the 33rd Annual Conference of the Forestry Association of Nigeria, vol. 2, pp. 136-147, Benin City, Edo State, Nigeria, October 2010.

[7] A. Demirbas, "Combustion of biomass," Energy Sources, Part A: Recovery, Utilization, and Environmental Effects, vol. 29, no. 6, pp. 549-561, 2007.

[8] P. Shukla, "Biomass energy future for India," in Proceedings of the International Workshop "Science and Technology for a Modern Biomass Civilization, Rio De Janeiro, Brazil, September 1997.

[9] R. Nosek, M. Holubcile, and J. Jandacka, "The impact of bark content of wood biomass on the biofuel properties," Bioresources, vol. 11, no. 1, pp. 44-53, 2016.

[10] Blazej, A., 1975, ChemiaDreva (Wood Chemistry), Vydevatelstvo Alfa, Bratislava.

[11] Dzurenda, L. and Jandacka, J., 2010, EnergetickeVyuziticdendromasy [energetic using of biomass], Vydavatelstvo TU voZvolene. 
[12] ASTM, Standard Test Method for Gross Calorific Value of Refuse-Derived Fuel by the Bomb Calorimeter (Withdrawn 2004), ASTM International, West Conshohocken, PA, USA, 2004, http://www.astm.org.

[13] R. T. Bailey and P. R. Blankehorn, "Calorific and porosity development in carbonized wood," Wood Science, vol. 15, no. 1, pp. 19-28, 1982.

[14] J. M. Bremner, "Determination of nitrogen in soil by the Kjeldahl method," The Journal of Agricultural Science, vol. 55, no. 1, pp. 11-33, 1960.

[15] TAPPI Test Method, "Solvent extractives of wood and pulp," in Tappi Test Methods, Technical Association of the Pulp and Paper Industry, Atlanta, GA, 1983.

[16] S. Y. Lin and C. W. Dence, Springer Series in Wood Science Methods in Lignin Chemistry, Springer Verlag, Berlin, Germany, 1992.

[17] D. Deka, P. Sedai, and R. S. Chutia, "Investigating woods and barks of some indigenous tree species in north-east India for fuel value analysis," Energy Sources, Part A: Recovery, Utilization, and Environmental Effects, vol. 36, no. 17, pp. 19131920, 2014.

[18] C. Telmo and J. Lousada, "The explained variation by lignin and extractive contents on higher heating value of wood," Biomass and Bioenergy, vol. 35, no. 5, pp. 1663-1667, 2011.

[19] R. Kataki and D. Konwer, "Fuelwood characteristics of some indigenous woody species of north-east India," Biomass and Bioenergy, vol. 20, no. 1, pp. 17-23, 2001.

[20] J. Nurm, "Measurement and evaluation of wood fuel," Biomass and Bio-Energy, vol. 2, no. 1-6, pp. 157-171, 1992.

[21] P. Álvarez-Álvarez, C. Pizarro, M. Barrio-Anta, A. CámaraObregón, J. Bueno, and D. Burslem, "Evaluation of tree species for biomass energy production in northwest spain," Forests, vol. 9, no. 4, p. 160, 2018.

[22] A. Demirbas and Y. Arin, "Carbonization ranking of selected biomass for charcoal, liquid and gaseous products," Energy Conversion and Management, vol. 42, pp. 1229-1238, 2002.

[23] C. Sheng and J. L. T. Azevedo, "Estimating the higher heating value of biomass fuels from basic analysis data," Biomass and Bioenergy, vol. 28, no. 5, pp. 499-507, 2005.

[24] R. Saidur, E. A. Abdelaziz, A. Demirbas, M. S. Hossain, and S. Mekhilef, "review on biomass as a fuel for boilers," Renewable and Sustainable Energy Reviews, vol. 15, no. 5, pp. 2262-2289.

[25] K.-E. Saarela, L. Harju, J. Rajander et al., "Elemental analysis of pine bark and wood in an environmental study/ science of the total environment," Science of The Total Environment, vol. 343, no. 1-3, pp. 231-241, 2015.

[26] R. García, C. Pizarro, A. G. Lavín, and J. L. Bueno, "Characterization of Spanish biomass wastes for energy use," Bioresource Technology, vol. 103, no. 1, pp. 249-258, 2012.

[27] G. Wang, J. Zhang, J. Shao et al., "Thermal behavior and kinetic analysis of co-combustion of biomass/low rank coal blends," Energy Conversion Management, vol. 124, pp. 414426, 2016.

[28] R. B. Miller, "Wood handbook-wood as an engineering material forest products laboratory," General Technical Report FPL; GTR-113, U.S. Department of Agriculture, Forest Service, Forest Products Laboratory, Madison, WI, USA, 1999.

[29] R. A. Nasser and I. M. Aref, "Fuelwood characteristics of six acacia species growing wild in the south west of Saudi Arabia as affected by geographical location," Bio-resources, vol. 9, no. 1, pp. 1212-1224, 2014.
[30] K. Demirbas and R. E. H. Sims, "Fuel characteristics of short rotation forest biomass," Biomass and Bioenergy, vol. 17, no. 2, pp. 127-140, 1999.

[31] E. T. Howard, "Heat of combustion of various southern pine materials," Wood Science, vol. 5, no. 3, pp. 194-197, 1973.

[32] R. H. White, "Effect of lignin content and extractives on higher heating value of wood," Wood Fiber Science, vol. 19, no. 4, pp. 446-452, 1987. 